\title{
Collaterals: an important determinant of prolonged ischemic penumbra versus rapid cerebral infarction?
}

\section{Elisabeth Breese Marsh ${ }^{1,2}$, Richard Leigh ${ }^{1}$, Martin Radvany ${ }^{3}$, Philippe Gailloud ${ }^{3}$ and Rafael H. Llinas ${ }^{1,2 *}$}

1 Department of Neurology, The Johns Hopkins University School of Medicine, Baltimore, MD, USA

2 Department of Neurology, Johns Hopkins Bayview Medical Center, Baltimore, MD, USA

${ }^{3}$ Department of Radiology, The Johns Hopkins University School of Medicine, Baltimore, MD, USA

Edited by:

Jean-Claude Baron, University of

Cambridge, UK

\section{Reviewed by:}

Alexander Tsiskaridze, Tbilisi State

University, Georgia

Wengui Yu, UT Southwestern Medical

Center at Dallas, USA

Jean-Claude Baron, University of

Cambridge, UK

${ }^{*}$ Correspondence:

Rafael H. Llinas, Department of Neurology, Johns Hopkins Hospital, 600 North Wolfe Street, Phipps 446, Baltimore, MD 21287, USA

e-mail: rllinas@jhmi.edu
Intravenous tissue plasminogen activator is the mainstay for the treatment of acute ischemic stroke in patients presenting within $4.5 \mathrm{~h}$ of symptom onset. Studies have demonstrated that treating patients early leads to improved long-term outcomes. MR imaging currently allows quantification of the ischemic penumbra in order to better identify individuals most likely to benefit from intervention, irrespective of "time last seen normal." Its increasing use in clinical practice has demonstrated individual differences in rate of infarction. One explanation for this variability is a difference in collateral blood flow. We report two cases that highlight the individual variability of infarction rate, and discuss potential underlying mechanisms that may influence treatment decisions and outcomes.

Keywords: penumbra, ischemic stroke, collaterals, intra-arterial thrombolysis, recovery

\section{INTRODUCTION}

Intravenous tissue plasminogen activator (IV tPA) is approved by the FDA for the treatment of acute ischemic stroke for patients presenting within $3 \mathrm{~h}$ of symptom onset. Additional benefit has been shown within the $4.5 \mathrm{~h}$ window $(1,2)$. Subsequent studies have demonstrated improved outcomes for patients treated early, indicating that time is an important factor in determining the success of thrombolysis (3). This is most likely because vessel occlusion results in a poorly perfused ischemic core those infarcts rapidly, with a larger area of marginally perfused tissue, or penumbra (4). Neurons within the hypoperfused area are unable to maintain a resting potential, resulting in clinical dysfunction, but are not yet irreversibly damaged (5). The time that is required for the ischemic core to expand to match the penumbra is variable from patient to patient. One study showed that $91 \%$ of patients had a favorable diffusion (core) to perfusion (penumbra) mismatch on neuroimaging within $3 \mathrm{~h}$ from "last seen normal" falling to $72 \%$ by 3-6h post-symptom onset $(6,7)$. Importantly, a small group of patients continued to display a favorable mismatch up to $24 \mathrm{~h}$ from symptom onset. We present two cases that demonstrate this individual variability of infarct progression.

\section{CASE PRESENTATION}

\section{CASE 1}

WS is a 70-year-old man with a history of hypertension, hyperlipidemia, and diabetes, who presented with aphasia and a right hemiparesis. He was last seen normal by his wife at 9 p.m. the evening prior to admission. When she came to bed at 2 a.m. she noted that he could not move his right side or communicate, and called EMS. He arrived in the Emergency Department at 2:34 a.m. His blood pressure was $121 / 60 \mathrm{mmHg}$. Serum glucose was
126. He was noted to be in atrial fibrillation. His troponin was elevated at 7.12 with mild ST segment changes. His NIH stroke scale was 12 , with points given for disorientation, gaze preference, dysarthria, aphasia, and hemiparesis. He was outside of the window for treatment with IV tPA. Work-up was initiated. He vomited during CT angiogram, requiring intubation for airway protection. Coffee ground emesis was also noted. Cerebral perfusion was maximized with fluids and positioning and he was admitted to the Neurocritical Care Unit for further monitoring. Permissive hypertension was allowed as per our institution's policy regarding treatment of acute stroke; however, his systolic blood pressures remained around $120 \mathrm{mmHg}$. He did not exhibit evidence of perfusion dependence on examination so hypertensive therapy was not pursued. Due to medical instability, an MRI of the brain was not performed until the following morning. Neuroimaging revealed a large perfusion deficit encompassing much of the left middle cerebral artery (MCA) territory, matching his clinical deficits, with no clear diffusion abnormality (Figures 1A,B). He remained symptomatic, and the decision was made to proceed with intra-arterial intervention given the lack of infarcted tissue. Over $16 \mathrm{~h}$ after being last seen normal, successful recanalization was achieved using the penumbra clot retrieval device. Angiography demonstrated robust collateral flow through the pial vessels (Figure 2A). Follow-up MR imaging showed only a small area of diffusion restriction. His aphasia and hemiparesis markedly improved after recanalization, and 4 days later he walked out of the hospital with no rehabilitation needs.

\section{CASE 2}

LD is an 86-year-old woman with a history of hypertension, hyperlipidemia, and recurrent breast cancer, who presented with right 


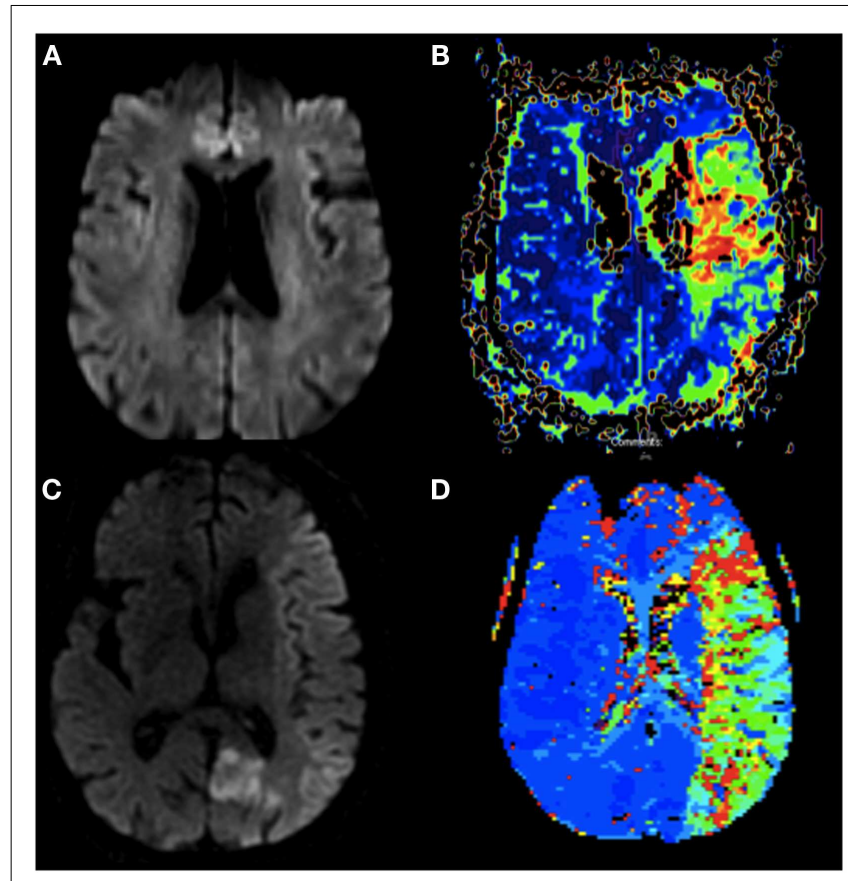

FIGURE 1 | (A) Diffusion weighted imaging of Case 1 without evidence of infarction $16 \mathrm{~h}$ after onset of symptoms. (B) Perfusion weighted imaging (TTP) of Case 1 showing patchy hypoperfusion of the left MCA.

(C) Diffusion weighted imaging of Case $2<60 \mathrm{~min}$ from stroke onset with early changes throughout the entire left MCA territory and her prior subacute left PCA infarct. (D) Perfusion weighted imaging (TTP) of Case 2 showing hypoperfusion of the entire left MCA.

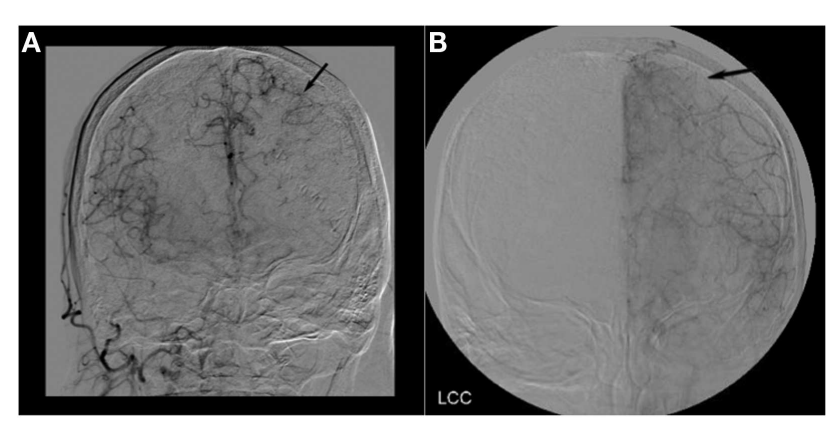

FIGURE 2 | (A) Cerebral angiogram of Case 1 showing robust collateral flow through the pial vessels in the late arterial phase (black arrow). (B) Cerebral angiogram of Case 2 showing a lack of collateral flow through the pial vessels in the late arterial phase (black arrow).

sided weakness and vision loss. She was last seen normal the night prior to admission and was therefore not an IV tPA candidate. An MRI of the brain showed diffusion restriction within the left posterior cerebral artery territory. A CT angiogram showed mild atherosclerotic changes. She was awaiting a transthoracic echocardiogram prior to discharge and recovering well until hospital day 3. At 9:40 a.m. she walked to the bathroom unassisted, but was found $3 \mathrm{~min}$ later by the neurology team to be aphasic, with left gaze deviation, and a dense right hemiparesis. Her NIH stroke scale was 19. A head CT showed no intracranial hemorrhage, but a hyperdense left MCA sign. Acute ischemia was suspected. Given her recent PCA stroke she was again not a candidate for IV tPA. A hyperacute MRI was completed $<60$ min after the onset of symptoms to determine if she was a candidate for intra-arterial intervention. Despite the short time between symptom onset and imaging, a significant area of new restricted diffusion involving mainly the cortex was noted within the left hemisphere, along with a larger perfusion deficit and cut off of the M1 branch of the left MCA (Figures 1C,D). Given the acute onset of symptoms and presence of a diffusion/perfusion mismatch, the decision was made to proceed with intervention. Angiography demonstrated a lack of collaterals without significant flow through the pial vessels (Figure 2B). Unfortunately, despite complete recanalization within $4 \mathrm{~h}$ of symptom onset, a large portion of the MCA territory was infarcted on follow-up imaging. She remained aphasic and densely hemiparetic through to discharge to a rehabilitation facility.

\section{DISCUSSION}

MRI and CT perfusion allow real-time quantification of infarcted versus hypoperfused tissue; however, the trials looking at the use of MR imaging to predict who will benefit from late recanalization have been mixed (8-12). Therefore, time from symptom onset continues to be the standard indicator of which patients will benefit most from recanalization. Here, we describe two cases that illustrate the individual variability in the time course of infarction between patients presenting with large vessel occlusion. In Case 1, time of recanalization was prolonged from stroke onset, yet irreversible damage was minimal. Additional cases have been reported in the literature, with viable tissue being documented up to $17 \mathrm{~h}$ from stroke onset (13-15). In Case 2, after only $60 \mathrm{~min}$, a significant portion of the vascular territory had already undergone infarction. In both cases, response to treatment paralleled imaging characteristics, but did not parallel the outcomes predicted by time alone.

The increased availability of MRI and advent of perfusion imaging techniques provide an opportunity to identify patients with a "favorable ischemic profile" independent of time from stroke onset (12). This favorable profile appears more common in the hyperacute setting, but as illustrated above, prolonged mismatches may occur. Conversely, unfavorable mismatches can also occur after only a short period of vessel occlusion (16). Correctly identifying both groups may help to tailor therapy beyond current guidelines. Studies looking for the favorable profile have, to date, yielded mixed results (8-12). It is likely that we simply have yet to consistently identify the right subgroup who will benefit, and/or have failed to account for an additional critical unmeasured variable. One reason that studies like MR RESCUE (8) have been disappointing may be because perfusion weighted imaging likely does not adequately take into account collateral blood flow, and that slowed flow is not the same as absent flow. In MR RESCUE, the information obtained was "presence of a mismatch," but at no point was comment made regarding presence of favorable collateral blood flow on angiogram, which we believe would have been useful information in deciding whether to move forward with recanalization. Though these studies have 
failed to give rise to definitive criteria that reliably predict good long-term outcome, they have confirmed the presence of a select group who continue to have significant diffusion/perfusion mismatches far outside the accepted $4.5 \mathrm{~h}$ window (12). While it is statistically more likely for a favorable mismatch to occur early, failing to account for these individuals would result in a missed opportunity for intervention given their prolonged therapeutic window $(6,17)$.

In an elegant set of experiments, Jones et al. showed that with a reduction of cerebral blood flow $(\mathrm{CBF})$ in an animal occlusion model, the amount of reduced flow predicted irreversible infarction. They found that reduction of local CBF in the range of $23 \mathrm{cc} / 100 \mathrm{gm} / \mathrm{min}$ resulted in reversible paralysis without infarction once blood flow was reinstated. Of interest, reduction of local CBF further to $10-12 \mathrm{cc} / 100 \mathrm{gm} / \mathrm{min}$ for $2-3 \mathrm{~h}$ resulted in irreversible infarction (18). In humans with acute stroke, the specific factors that determine rate of infarction and the local CBF remain unclear; however, the primary contributor is likely the presence versus absence of viable collaterals. Collateral flow through the pial vessels was clearly evident on the angiogram in our "late infarcter" (Case 1), but poorly visualized in our "early infarcter" (Case 2) (19). Prior studies looking at both digital subtraction angiography (DSA) and CT angiography in predicting outcomes of thrombolysis have shown similar results, confirming that those with better long-term outcomes typically exhibit more robust flow through the collaterals $(20,21)$.

If rate of infarction is dependent on the presence of viable collaterals, it is important to consider factors that may influence collateral flow. Collaterals may be seen in response to acute vascular occlusion, or as the result of chronic stenosis of a single vessel (i.e., Moyamoya syndrome). Patients who are younger and those with a lower atherosclerotic burden may have the ability to muster better acute collateral flow (22). When relatively healthy pial vessels are successfully recruited following an MCA occlusion, the resulting infarct often spares much of the cortex, rather than involving the entire vascular territory $(23,24)$. Similarly, vascular stenosis of a single large artery stimulates chronic collateralization within the vascular bed, making the specific territory more resistant to ischemia should the vessel occlude.

In addition to collateral blood flow, when there is a chronic low-flow state or vascular stenosis, ischemic preconditioning may occur. This phenomenon was first described in the cardiac literature and has been well demonstrated in MCA occlusion models (25). In humans, it has been observed that patients undergoing balloon occlusion, and those with prior transient ischemic attacks, have smaller strokes when the same vascular distribution is subsequently compromised $(26,27)$. It seems that brain exposed to chronic ischemia (i.e., large vessel stenosis) is better able to tolerate future ischemic events due to physiologic and molecular changes within the affected neurons (25).

Our cases, in the context of these prior studies, support the concept that the combination of robust collateral blood flow (either acutely or chronically) and some degree of existing ischemic preconditioning, in conjunction with other factors such as the metabolic demand of the at risk tissue (with gray matter areas being most at risk) and systolic blood pressure affecting overall cerebral perfusion, results in patients who are "late infarcters"
(28). In Case 1, following clot retrieval it was apparent that WS had some degree of pre-existing MCA stenosis. This likely led to chronic collateralization, as evidenced by robust flow through his pial vessels. Unfortunately, the presence of favorable collaterals and prior ischemic preconditioning are not variables that can be easily determined on current MR imaging. Accordingly, they may be the critical variables missing from the prior "late thrombolysis" studies.

For the population as a whole, time remains the single most important variable used to predict who will benefit from thrombolysis. However, with advances in neuroimaging, a surrogate marker that allows better individualization of treatment would be ideal. Though expansion of the ischemic core likely occurs over a fairly predictable time course, we have shown two cases that illustrate significant variability. A better understanding of the role of collateral blood flow and ischemic preconditioning may allow us to better identify those individuals who may be "late infarcters," or even develop strategies to slow infarction rate.

\section{ACKNOWLEDGMENTS}

Elisabeth Breese Marsh is supported by a Johns Hopkins School of Medicine Clinician Scientist Award.

\section{REFERENCES}

1. The National Institute of Neurological Disorders and Stroke rt-PA Stroke Study Group. Tissue plasminogen activator for acute ischemic stroke. N Engl J Med (1995) 333:1581-8. doi:10.1056/NEJM199512143332401

2. Hacke W, Kaste M, Bluhmki E, Brozman M, Dávalos A, Guidetti D, et al. Thrombolysis with alteplase 3 to 4.5 hours after acute ischemic stroke. $N$ Engl J Med (2008) 359:1317-29. doi:10.1056/NEJMoa0804656

3. Strbian D, Ringleb P, Michel P, Breuer L, Ollikainen J, Murao K, et al. Ultra-early intravenous stroke thrombolysis: do all patients benefit similarly? Stroke (2013) 44:2913-6. doi:10.1161/STROKEAHA.111.000819

4. Kaufmann AM, Firlik AD, Fukui MB, Wechsler LR, Jungries CA, Yonas H. Ischemic core and penumbra in human stroke. Stroke (1999) 30:93-9. doi:10. 1161/01.STR.30.1.93

5. Hossmann KA. Viability thresholds and the penumbra of focal ischemia. Ann Neurol (1994) 36:557-65. doi:10.1002/ana.410360404

6. Llinas RH, Linfante I, Choi G, et al. Diffusion-perfusion lesion patterns in hyperacute stroke. Ann Neurol (2000) 48:455.

7. Harris AD, Kosior RK, Chen HS, Andersen LB, Frayne R. Evolution of hyperacute stroke over 6 hours using serial MR perfusion and diffusion maps. J Magn Reson Imaging (2009) 29:1262-70. doi:10.1002/jmri.21763

8. Kidwell CS, Jahan R, Gornbein J, Alger JR, Nenov V, Ajani Z, et al. A trial of imaging selection and endovascular treatment for ischemic stroke intervention. N Engl J Med (2013) 368:914-23. doi:10.1056/NEJMoa1212793

9. Ciccone A, Valvassori L, Nichelatti M, Sgoifo A, Ponzio M, Sterzi R, et al. Endovascular treatment for acute ischemic stroke. N Engl J Med (2013) 368:904-13. doi:10.1056/NEJMoa1213701

10. Broderick JP, Palesch YY, Demchuk AM, Yeatts SD, Khatri P, Hill MD, et al. The Interventional Management of Stroke (IMS) III Investigators. Endovascular therapy after intravenous t-PA versus t-PA alone for stroke. $N$ Engl J Med (2013) 368:893-903. doi:10.1056/NEJMoa1214300

11. Von Kummer R, Albers GW, Mori E; DIAS Steering Committees. The desmoteplase in acute ischemic stroke (DIAS) clinical trial program. Int J Stroke (2012) 7:589-96. doi:10.1111/j.1747-4949.2012.00910.x

12. Lansberg MG, Straka M, Kemp S, Mlynash M, Wechsler LR, Jovin TG, et al. MRI profile and response to endovascular reperfusion after stroke (DEFUSE 2): a prospective cohort study. Lancet Neurol (2012) 10:860-7. doi:10.1016/S14744422(12)70203-X

13. Marchal G, Serrati C, Rioux P, Petit-Taboué MC, Viader F, de la Sayette V, et al. PET imaging of cerebral perfusion and oxygen consumption in acute ischaemic stroke: relation to outcome. Lancet (1993) 341:925-7. doi:10.1016/ 0140-6736(93)91214-7 
14. Marchal G, Beaudouin V, Rioux P, de la Sayette V, Le Doze F, Viader F, et al. Prolonged persistence of substantial volumes of potentially viable brain tissue after stroke. A correlative PET-CT study with voxel-based data analysis. Stroke (1996) 4:599-606. doi:10.1161/01.STR.27.4.599

15. Baron JC. Mapping the ischaemic penumbra with PET: implications for acute stroke treatment. Cerebrovasc Dis (1999) 4:193-201. doi:10.1159/ 000015955

16. Inoue M, Mlynash M, Straka M, Lansberg MG, Zaharchuk G, Bammer $\mathrm{R}$, et al. Patients with the malignant profile within 3 hours of symptom onset have very poor outcomes after intravenous tissue-type plasminogen activator therapy. Stroke (2012) 43:2494-6. doi:10.1161/STROKEAHA.112. 653329

17. Toni D, Fiorelli M, Bastianello S, Falcou A, Sette G, Ceschin V, et al. Acute ischemic strokes improving during the first 48 hours of onset: predictability, outcome, and possible mechanisms: a comparison with early deteriorating strokes. Stroke (1997) 28:10-4. doi:10.1161/01.STR.28.1.10

18. Jones TH, Morawetz RB, Crowell RM, Marcoux FW, FitzGibbon SJ, DeGirolami $\mathrm{U}$, et al. Thresholds of focal cerebral ischemia in awake monkeys. J Neurosurg (1981) 54:773-82. doi:10.3171/jns.1981.54.6.0773

19. Liebeskind DS. Collateral circulation. Stroke (2003) 34:2279-84. doi:10.1161/ 01.STR.0000086465.41263.06

20. Nambiar V, Sohn SI, Almekhlafi MA. CTA collateral status and response to recanalization in patients with acute ischemic stroke. AJNR Am J Neuroradiol (2014) 35:884-90. doi:10.3174/ajnr.A3817

21. Abou-Chebl A. Endovascular treatment of acute ischemic stroke may be safely performed with no time window limit in appropriately selected patients. Stroke (2010) 41:1996-2000. doi:10.1161/STROKEAHA.110.578997

22. Caplan LR. Latest developments in collateral circulation, pediatric stroke, and stroke recovery. Rev Neurol Dis (2007) 4:153-6.

23. Yamauchi H, Kudoh T, Sugimoto K, Takahashi M, Kishibe Y, Okazawa H. Pattern of collaterals, type of infarcts, and haemodynamic impairment in carotid artery occlusion. J Neurol Neurosurg Psychiatry (2004) 75:1697-701. doi:10.1136/jnnp.2004.040261
24. Min WK, Park KK, Kim YS, Park HC, Kim JY, Park SP, et al. Atherothrombotic middle cerebral artery territory infarction. Stroke (2000) 31:2055-61. doi:10.1161/01.STR.31.9.2055

25. Zhao H. Ischemic post-conditioning as a novel avenue to protect against brain injury after stroke. J Cereb Blood Flow Metab (2009) 29:873-85. doi:10.1038/ jcbfm. 2009.13

26. Wegener S, Gottschalk B, Jovanovic V, Knab R, Fiebach JB, Schellinger PD, et al. Transient ischemic attacks before ischemic stroke: preconditioning the human brain? Stroke (2004) 35:616-21. doi:10.1161/01.STR.0000115767.17923.6A

27. Faries PL, DeRubertis B, Trocciola S, Karwowski J, Kent KC, Chaer RA. Ischemic preconditioning during the use of the percusurge occlusion balloon for carotid angioplasty and stenting. Vascular (2008) 16:1-9. doi:10.2310/6670.2008.00012

28. Marks MP, Lansberg MG, Mlynash M, Olivot JM, Straka M, Kemp S, et al. Effect of collateral blood flow on patients undergoing endovascular therapy for acute ischemic stroke. Stroke (2014) 45:1035-9. doi:10.1161/STROKEAHA.113. 004085

Conflict of Interest Statement: The authors declare that the research was conducted in the absence of any commercial or financial relationships that could be construed as a potential conflict of interest.

Received: 01 July 2014; accepted: 30 September 2014; published online: 14 October 2014.

Citation: Marsh EB, Leigh R, Radvany M, Gailloud P and Llinas RH (2014) Collaterals: an important determinant of prolonged ischemic penumbra versus rapid cerebral infarction? Front. Neurol. 5:208. doi: 10.3389/fneur.2014.00208 This article was submitted to Stroke, a section of the journal Frontiers in Neurology. Copyright (c) 2014 Marsh, Leigh, Radvany, Gailloud and Llinas. This is an open-access article distributed under the terms of the Creative Commons Attribution License (CC $B Y)$. The use, distribution or reproduction in other forums is permitted, provided the original author(s) or licensor are credited and that the original publication in this journal is cited, in accordance with accepted academic practice. No use, distribution or reproduction is permitted which does not comply with these terms. 